\title{
Latin American consensus on guidelines for chronic migraine treatment
}

\author{
Consenso latino-americano para as diretrizes de tratamento da migrânea crônica
}

Alex Rodrigo Espinoza Giacomozzi', Alexander Parajeles Vindas², Ariovaldo Alberto da Silva Junior³, Carlos Alberto Bordini4, Carlos Federico Buonanotte 5 , Célia Aparecida de Paula Roesler ${ }^{6}$. Cláudio Manoel Brito7, Cristina Perez ${ }^{8}$, Deusvenir de Souza Carvalho ${ }^{9}$, Djacir Dantas Pereira de Macedo ${ }^{10}$, Elcio Juliato Piovesan ${ }^{11}$, Elder Machado Sarmento ${ }^{12}$, Eliana Meire Melhado ${ }^{13}$, Fabiola Dach Éckeli14, Fernando Kowacs ${ }^{15}$, Fidel Sobrino ${ }^{16}$, Getúlio Daré Rabello ${ }^{17}$, Grisel Rada ${ }^{18}$, Jano Alves de Souza ${ }^{19}$, Juana Rosa Casanovas ${ }^{20}$, Juan Carlos Durán ${ }^{21}$, Leandro Cotoni Calia ${ }^{22}$, Luis Roberto Partida Medina ${ }^{23}$, Luiz Paulo de Queiroz ${ }^{24}$, Marcelo Cedrinho Ciciarelli25, Marcelo Moraes Valença ${ }^{26}$, Maria Cusicanqui ${ }^{27}$, Maria Karina Velez Jimenez ${ }^{28}$, Maria Tereza Goycochea ${ }^{29}$, Mário Fernando Prieto Peres ${ }^{30}$, Mario Victor Fuentealba Sandoval ${ }^{31}$, Maurice Borges Vincent ${ }^{32}$, Michel Volcy Gomes ${ }^{33}$, Mónica Diez ${ }^{34}$, Nayeska Aranaga ${ }^{35}$, Nelson Barrientos ${ }^{36}$, Pedro André Kowacs ${ }^{37}$, Pedro Ferreira Moreira Filho ${ }^{38}$

\footnotetext{
'Universidad de Santiago de Chile and Sociedad de Neurología, Psiquiatría y Neurocirugía (Sonepsyn), Santiago de Chile, Chile;

${ }^{2}$ Universidad de Costa Rica, Hospital San Juan de Dios, Costa Rica;

${ }^{3}$ Universidade Federal de Minas Gerais (UFMG), Universidade José do Rosário Vellano (Unifenas), Hospital das Clínicas of UFMG, Belo Horizonte MG, Brazil; ${ }^{4}$ Faculdade de Medicina de Ribeirão Preto, Universidade de São Paulo (USP), Faculdade de Medicina Barão de Mauá, São Paulo SP, Brazil;

${ }^{5}$ Universidad Nacional de Córdoba, Província de Córdoba, Argentina;

${ }^{6}$ Academia Brasileira de Neurologia, Brazilian and International Headache Societies, São Paulo SP, Brazil;

־Universidade Federal Fluminense (UFF), Centro Universitário de Volta Redonda, Volta Redonda SP, Brazil;

${ }^{8}$ Facultad de Medicina de la Universidad de la República, Hospital Maciel, Montevideo, Uruguay;

'Sector of Investigation and Treatment of Headaches at Clinical Neurology in the Neurology Discipline, Escola Paulista de Medicina (EPM), Universidade Federal de São Paulo (UNIFESP), São Paulo SP, Brazil;

${ }^{10}$ Universidade Federal do Rio Grande do Norte (UFRN), Natal RN, Brazil;

${ }^{11}$ Universidade Federal do Paraná (UFPR), Curitiba PR, Brazil;

${ }^{12}$ UFF, Associação Latino-Americana de Cefaleia, Rio de Janeiro RJ, Brazil;

${ }^{13}$ Universidade Estadual de Campinas (Unicamp), Faculdade de Medicina de Catanduva, Catanduva SP, Brazil;

${ }^{14}$ Faculdade de Medicina de Ribeirão Preto, USP, Ribeirão Preto SP, Brazil;

${ }^{15}$ Academia Brasileira de Neurologia, Universidade Federal de Ciências da Saúde de Porto Alegre, Porto Alegre RS, Brazil;

${ }^{16}$ Universidade de La Sabana, Bogotá, Colombia;

${ }^{17}$ Faculdade de Medicina da USP, São Paulo SP, Brazil;

${ }^{18}$ Hospital Pérez Carreño, Caracas, Venezuela;

${ }^{19}$ UFF, Rio de Janeiro RJ, Brazil;

${ }^{20}$ Universidad Mayor de San Andrés, La Paz, Bolivia;

${ }^{21}$ Hospital Vargas de Caracas from Universidad Central de Venezuela, Caracas, Venezuela;

${ }^{22}$ Escola Paulista de Medicina da UNIFESP, Universidade de Santo Amaro, São Paulo SP, Brazil;

${ }^{23}$ Universidad de Guadalajara, Mexico;

${ }^{24}$ Universidade Federal de Santa Catarina, UNIFESP, São Paulo SP, Brazil;

${ }^{25}$ Faculdade de Medicina de Ribeirão Preto, USP, Centro Educacional Barão de Mauá, Ribeirão Preto SP, Brazil;

${ }^{26}$ Universidade Federal de Pernambuco, Recife PE, Brazil;

${ }^{27}$ Hospital das Clínicas, Universidad Mayor de San Andrés, La Paz, Bolivia;

${ }^{28}$ Hospital Especialidades Centro Médico La Raza, Academía Mexicana de Neurología, Mexico;

${ }^{29}$ Sociedad Neurológica, Argentina;

${ }^{30}$ UNIFESP, Hospital Israelita Albert Einstein, São Paulo SP, Brazil;

${ }^{31}$ Universidad de Concepción, Chile;

${ }^{32}$ University of Trondheim, Norway, Faculdade de Medicina da Universidade Federal do Rio de Janeiro (UFRJ) and Hospital Universitário Clementino Fraga Filho (HUCFF) of UFRJ, Rio de Janeiro RJ, Brazil;

${ }^{33}$ ASS Colombiana de Neurología and AHS, Medellin, Colombia;

${ }^{34}$ Universidad de Buenos Aires, Buenos Aires, Argentina;

${ }^{35}$ Universidad Central de Venezuela and Hospital Vargas, Caracas, Venezuela;

${ }^{36}$ Universidad Diego Portales, Universidad de Santiago, Santiago de Chile, Chile;

${ }^{37}$ Instituto de Neurologia, Curitiba PR, Brazil;

${ }^{38}$ Medicine School of UFF, Rio de Janeiro RJ, Brazil.

Correspondence: Marcelo Moraes Valença; Rua General Abreu e Lima 155 / apto. 801; 52041-040 Recife PE - Brasil; E-mail: mmvalenca@yahoo.com.br Conflict of interest: There is no conflict of interest to declare.

Received 22 November 2012; Received in final form 13 March 2013; Accepted 20 March 2013.
} 


\section{ABSTRACT}

Chronic migraine is a condition with significant prevalence all around the world and high socioeconomic impact, and its handling has been challenging neurologists. Developments for understanding its mechanisms and associated conditions, as well as that of new therapies, have been quick and important, a fact which has motivated the Latin American and Brazilian Headache Societies to prepare the present consensus. The treatment of chronic migraine should always be preceded by a careful diagnosis review; the detection of possible worsening factors and associated conditions; the stratification of seriousness/impossibility to treat; and monitoring establishment, with a pain diary. The present consensus deals with pharmacological and nonpharmacological forms of treatment to be used in chronic migraine.

Key words: migraine, treatment, headache.

\section{RESUMO}

A migrânea crônica é uma condição com prevalência significativa ao redor do mundo e alto impacto socioeconômico, sendo que seu manuseio tem desafiado os neurologistas. Os avanços na compreensão de seus mecanismos e das condições a ela associadas, bem como nas novas terapêuticas, têm sido rápidos e importantes, fato que motivou as Sociedades Latino-americana e Brasileira de Cefaleia a elaborarem o presente consenso. 0 tratamento da migrânea crônica deve ser sempre precedido por uma revisão cuidadosa do diagnóstico, pela detecção de possiveis fatores de piora e das condições associadas, pela estratificação de gravidade/impossibilidade de se tratar e pelo monitoramento com um diário da dor. Este consenso apresenta abordagens farmacológicas e não-farmacológicas para tratar a migrânea crônica.

Palavras-Chave: migrânea, tratamento, cefaleia.

The International Headache Classification (ICHD-2) is the result of a huge effort for preparing a taxonomic system on different conditions in which headaches are present, with over 200 morbid conditions catalogued on its second edition, in $2004^{1}$.

Headaches can be divided, in a simplified manner, into two groups:

- primary, conditions in which mechanisms are eminently neurochemical;

- secondary or 'attributed to', when there is a clear mechanism very likely to cause it, such as a headache due to bacterial meningitis.

Migraine is the typical example of primary headache. It is about a recurring neurological illness, at times progressive and highly prevalent. Typically, its attack is characterized by moderate-to-severe, predominantly lateralized and pulsatile headache, aggravated by physical exertion. This is frequently associated with nausea, vomit, photophobia, and phonophobia. Affected individuals should have normal physical and neurological examinations.

The word chronic is used in the ICHD-2 in three different scenarios: to refer to headaches that persist for a period longer than three months subsequent to the event that has originated it or after the originating process has already been solved (for example, chronic post-traumatic headache); to refer to headaches that persist for a period longer than that convened for characterizing a given headache as episodic (for example, chronic cluster headaches); when the headache occurs 15 or more days per month for over three months, which is the meaning of the word 'chronic' in chronic migraine.

Chronic migraine is a condition with significant prevalence all around the world and a high socioeconomic impact, and its handling has been challenging neurologists.
Developments in the understanding of its mechanisms and associated conditions, as well as that of new therapies, have been quick and important, a fact which has motivated the Latin American and Brazilian Headache Societies to prepare the present consensus.

\section{EPIDEMIOLOGY}

According to the World Health Organization (WHO), in 2011, headaches represent one of the most frequent reasons for medical appointments, migraines being amongst the 20 most disabling diseases ${ }^{2}$. This modality shows an annual prevalence from 3.0 to $24.6 \%$ of the world population, and a recent paper states that it can reach up to $27.5 \%^{3}$. It affects 2.9 to $7.8 \%$ of males and 10.1 to $17.4 \%$ of females in Latin America.

The concept of chronic daily headache was published in 1994 as a heterogeneous group of primary headaches with minimum duration of four hours per day and occurrence in 15 or more days per month, during the last three months. Chronic tension-type headache, transformed migraine, new daily persistent headache, and hemicrania continua have been included in chronic daily headache, transformed migraine being highlighted as the main cause. The ICHD-2 was published in 2004, introducing the word "chronic headache", which diagnostic criteria, also causing discussions, were modified in 2006. These lack of criteria unification makes epidemiological studies difficult.

According to the WHO, the annual prevalence of chronic daily headache is from 1.7 to $4.0 \%$ of the adult population, and chronic migraine represents approximately half of the cases. In systematic reviews of world population studies, the prevalence of chronic migraine oscillates between 0.9 and $5.1 \%$. 
Epidemiological studies on chronic migraine in Latin America reveal the following prevalence: 5.12\% in Brazil, 6.9\% in Cuba, and 7.76 in Colombia (evidences B and C). There are no incidence studies in Latin America.

According to analyses carried out in the United States, the prevalence of chronic migraine in adolescents varies from 0.76 and $1.48 \%$. There are no data for this population group in Latin America.

About $50 \%$ of people with headaches are self-medicated, and a frequent problem is the excessive use of symptomatic medication, whose diagnostic criteria are defined by the International Headache Society (IHS) ${ }^{1}$. Published papers inform that on a prevalence of approximately $1.4 \%$ of headaches are attributed to the excessive use of medication in the population in general, and in specialized centers this percentage increases up to 30 to $50 \%$ 6,7. In patients with chronic migraine, 31 to $69 \%$ of them show excessive use of medication ${ }^{4}$. Specialized centers in Latin America reported 55 to $70 \%^{8}$.

The natural history of chronic migraine reveals that $26.1 \%$ return to the episodic migraine condition, 33.9\% persist with chronic migraine, and $40 \%$ made a continuous transition between the episodic and chronic forms. The rate of conversion from chronic to episodic migraine will increase with age, varying 1.7 (20-year-old) to 7.1\% (60-year old) in females; and 4.2 (20-year-old) to $8.3 \%$ (60-year-old) in males.

As compared to episodic migraine, the chronic form causes more disability, has a greater impact on the quality of life, and leads to an increased use of health services and number of comorbidities ${ }^{10}$.

The annual direct cost of chronic migraine is estimated in US\$ 4,144.00 and US\$ 1,883.00 per patient in the health systems of the United States and Canada respectively. Correspondent expenses for patients with episodic migraine are US\$ 1,533.00 and US\$ 687.00. There are no data available for Latin America ${ }^{11}$.

It is worth mentioning that there are important barriers for investigating and handling headaches in all levels, with lack of governmental policies, little repercussion of information on decision-making levels, sub-notification of the socioeconomic impact of these diseases on the health system, and training of graduation and post-graduation students ${ }^{2}$.

\section{EVOLUTION OF THE CHRONIC MIGRAINE CONCEPT FROM CHRONIC DAILY HEADACHE}

Chronic daily headache is a descriptive word encompassing different types of headaches, which are characterized by symptoms occurring at least 15 days per month over more than three months, lasting at least four hours per day, in the absence of organic diseases ${ }^{12,13}$.

Chronic migraine is a disabling disease. Several names were given in an attempt to classify it: chronic mixed headache $\mathrm{e}^{14}$, transformed migraine $\mathrm{e}^{13,15}$, and chronic migraine ${ }^{1,16}$. Currently, the IHS defines it as shown on Table 1.

\section{Headache attributed to the excessive use of drugs up to the current classification}

A headache attributed to the excessive use of painkillers or anti-migraine medication is of the secondary chronictype. It is a result of the interaction between the therapeutic agent and the patient's susceptibility.

This problem was referred to as "rebound headache" until 2004. The IHS classification included item "headache attributed to the excessive use of medication", in which the diagnostic criteria include the excessive regular use of one or more medication that may be taken for acute or symptomatic treatment of headache for over three months. Criteria for excessive use of medication, as well as the obligatoriness of headache relief within two months subsequent to the suspension of the excessively used medication were set up on that occasion for diagnosing chronic migraine ${ }^{1}$.

As of 2006, it was proposed that the diagnosis should be made at the moment of the consultation, thus eliminating the previous criteria ${ }^{16}$. Patients increase their headaches by the excessive use of painkillers (Table 2).

It has been noted in the clinical practice that chronic migraine may occur with or without the excessive use of medication.

\section{Mechanisms}

Migraine chronification is a gradual process. Attacks evolve from being sporadic to frequent and, eventually, daily or almost daily. This mechanism is bidirectional, and spontaneous, or induced remission may take place. This phenomenon shows clinical, functional, and structural alterations ${ }^{17,18}$.

Table 1. Criteria for chronic migraine diagnosis ${ }^{16}$.

A: Headache occurring 15 or more days per month, for over
three months
B: Previous diagnosis of episodic migraine with no aura
C: Over eight days per month: headache with migraine criteria or
relief of headache with triptans or ergotics
D: Without excessive use of painkillers

Table 2. Criteria of headaches attributed to the excessive use of medication for several substances according to the International Headache Classification (ICHD-II) .

A: The headache occurs 15 or more days per month

B: Regular consumption of one or more medications for acute symptomatic treatment, defined in the following subtypes:

Noncombined common painkillers: ingestion at least 15 days per month for at least three months

ergotamine, triptans, opiates, or combined painkillers: ingestion at least ten days per month for at least three months

$\mathrm{C}$ : The headache developed or was significantly aggravated in the period of excessive use 
The physiopathological mechanism of chronic migraine has not been set up yet. It is probably a multiple-factor disorder, with the participation of more than one level of the nervous system. The central hypersensitivity of the trigeminal vascular complex ${ }^{19-21}$ increases excitability or reduces pain inhibitory mechanisms. The high frequency of migraine attacks and genetic susceptibility favor this physiopathological mechanism, among other factors, such as comorbidities.

\section{COMORBIDITIES}

Comorbidity is the occurrence of two or more conditions in a patient, in a frequency higher than that expected by chance.

There is evidence of comorbidity between migraine and cerebrovascular diseases, psychiatric disorders, and neurological diseases.

\section{Cerebrovascular diseases}

Subclinical ischemic lesions on the posterior circulation are more frequent in patients with migraine, especially those with aura ${ }^{22}$. Furthermore, ischemic encephalic vascular accidents (EVAs) and migraine are associated ${ }^{23}$. Ischemic EVA is more prevalent in chronic migraine than in the general population; comparatively, episodic migraine shows greater comorbidity with ischemic EVA than chronic migraine ${ }^{24}$, which is also significantly less associated with family history of EVA than episodic migraine ${ }^{25}$.

\section{Cardiovascular diseases}

Migraine, especially the one with aura, is associated with greater incidence of myocardial infarction and vascular claudication $^{26}$. There is no data in the literature showing the association between cardiovascular diseases and chronic migraine. First papers suggest the association between migraine and patent foramen ovale ${ }^{27}$, but this has not been confirmed in subsequent studies ${ }^{28}$. There are no specific papers on the association of patent foramen ovale and chronic migraine.

\section{Psychiatric disorders}

Mood disturbances, anxiety, and migraine are comorbid conditions $^{29}$. There are few studies on comorbidity between chronic migraine and depression. Chronic migraine has revealed comorbidity with greater depression, dysthymia, bipolar disorder, generalized anxiety disorder, compulsiveobsessive disorder, somatizations, and phobias in both the population as a whole and in those who seek specialized clinics $^{30}$. A study suggests lack of association between chronic migraine and compulsive-obsessive disorder ${ }^{24}$.

\section{Other neurological disorders}

There is evidence of comorbidity between episodic migraine and other neurological conditions ${ }^{24}$, such as epilepsy ${ }^{31}$, Ménière syndrome, benign paroxysmal positional vertigo, kinetosis ${ }^{32}$, and multiple sclerosis ${ }^{33}$. As to chronic migraine and epilepsy, a study has revealed no comorbidity ${ }^{31}$. There are no papers on chronic migraine and other neurological conditions.

\section{Other diseases}

Chronic migraine is comorbid with systemic arterial hypertension, hyperlipidaemia, sinusitis, asthma, pulmonary emphysema, peptic ulcer, insomnia, and fibromyalgia ${ }^{24,34,35}$. The irritable bowel syndrome is comorbid with migraine ${ }^{36}$, however no data are available regarding its association with the chronic one.

The relation between headaches and temporomandibular headaches is controversial, although comorbidity is described with migraine ${ }^{37,38}$.

\section{Risk factors}

Risk factors for migraine chronification are divided into: unmodifiable (or not easily modifiable) that include age, females, Caucasian ethnicity, genetic factors, and low educational and socioeconomic levels; and modifiable, which is described as follows.

\section{Frequency of attacks}

The higher the frequency of migraine attacks, the higher the risk of chronification. Compared to patients with zero to four days of headache per month, those with five to nine days have six-fold more chances to develop chronic daily headache, including chronic migraine. Patients with 10 to 14 days of headache show 20-fold higher risk ${ }^{39}$.

\section{Excessive use of pain medication}

The risk of patients that make excessive use of pain medication to develop chronic migraine is 19-fold higher as compared to those who do not ${ }^{39}$. Medication utilized in acute treatment of migraine demonstrates different potentials to induce chronification with opioids and barbiturates, regardless of use frequency, this risk increases. On the other hand, the controlled use of triptans (less than ten days per month) showed no potential for significant chronification. Non-hormonal anti-inflammatory medicine (less than ten days per month) is associated with reduction of migraine chronification risk ${ }^{40}$.

\section{Obesity}

A body mass index equal or higher than 30 is a risk factor for the development of chronic daily headache ${ }^{41}$. The Odds Ratio for overweight patients to develop chronic migraine is 1.4, 1.7 for obese and 2.2 for morbidly obese patients, as compared to those with normal weight ${ }^{42}$.

\section{Snoring}

Snoring is twice more prevalent in patients with chronic daily headaches than in those with episodic headache, possibly being an independent risk for 
progression $^{43}$. There is no specific data available for chronic migraine.

\section{Caffeine consumption}

Consumption of more than $241 \mathrm{mg}$ of caffeine per day has revealed a moderate risk factor for transforming episodic into chronic headache in females under 40 years of age. Moreover, it has been shown that subjects with chronic daily headaches consume more caffeine-based painkillers than those with episodic ones, especially females under 40 years old with migraine ${ }^{44}$. There is no specific data available for chronic migraine.

\section{Psychiatric comorbidities and stressing events}

Chronic migraine is three-fold more frequent in patients with anxiety and depression as compared to those without psychiatric comorbidities ${ }^{45}$. Chronic migraine was also more frequent in people presenting important changes in their lives during the last year, such as separation, financial losses, and loss of family members ${ }^{46}$.

\section{POSSIBLE CIRCUMSTANCES SUGGESTING THE HOSPITALIZATION OF MIGRAINE PATIENTS}

Eventually, a patient with chronic migraine might need to be hospitalized. Circumstances for patient's admission might be related to the treatment of the disease itself, its complications, adverse effects of medicines, and associated diseases. Hospitalization can also occur for a diagnosis review. The other further recommendations are based on good clinical practice standards.

Situations when hospitalization should be considered:

- lack of response to adequate treatment, under outpatient regime;

- history of frequent care in emergency unit;

- migraine state or refractory crisis regarding acute treatment at the emergency unit;

- intense nausea, vomits or diarrhea, resulting in dehydration, hydroelectrolyctic disorder, and/or impeding oral treatment, and special attention should be paid to conditions like pregnancy, puerperium, chronic renal failure, serious ischemic heart disease, and arrhythmias;

- changes in hemodynamic (blood pressure and heart rate) and respiratory (respiration rate and $\mathrm{O} 2$ saturation) data;

- necessity of interrupting the excessive use of symptomatic medicines (acute analgesics and anti-migraine medicines) and the treatment of manifestations related to toxicity and/or dependence/rebound phenomena that cannot be safely handled in an outpatient regime (parenteral treatment and/or intensive monitoring of symptoms);

- sub-intrant epileptic seizures or status epilepticus, serious allergic reactions, renal or hepatic failure, thrombocytopenia, bleeding, vascular insufficiency, serious infection;

- concomitant need of psychiatric hospitalization (risk of aggression, suicide, moral exposure, serious psychosis, detoxification of drug addicts, abstinence);

- when diagnosis review requires procedures better performed within a hospital regime; and

- presence of psychosocial factors impeding an adequate treatment outside a controlled environment.

\section{TRADITIONAL THERAPEUTIC APPROACH: PHARMACOLOGIC AND NON-PHARMACOLOGIC}

The treatment of chronic migraine should always be preceded by a careful diagnosis review; the detection of possible worsening factors and associated conditions; the stratification of seriousness/impossibility to treat; and the establishment of monitoring, with a pain diary.

Complementary diagnostic investigations shall be accomplished in accordance with anamnesis and prior examination review, by considering comorbid or associated diagnoses ${ }^{47}$.

Including a possible chronic migraine associated with a probable headache caused by excessive use of analgesics, one should give priority to a prophylactic against an acute treatment. In case pain symptoms are restrictive, one should stimulate analgesia through non-pharmacological methods. However, intense and/or impairing headaches (rebound/ exacerbations) should be treated in a vigorous way.

\section{Objective of chronic migraine treatment}

It is fundamental to consider the expectance of the patient regarding the treatment. This aims at reducing the frequency and intensity of crises, and improving his/her response to acute treatment by diminishing their impact over his/her quality of life $e^{48,49}$.

The approach to chronic migraine involves the following modalities of treatment: crises, transition, and preventive.

\section{Symptomatic treatment of headache crises (exacerbation)}

The headache pharmacologic treatment should consider: the excessively used medication associated with it; scenario (if out- or in-hospital); drug formulation (if oral or parenteral); drug efficacy regarding pain intensity; its potential to result in addiction; history of intolerance and idiosyncratic responses; pharmacodynamics profile; response to previous acute treatments; and patient's stratification regarding the degree of lack of clinical response with acute treatments ${ }^{50,51}$.

There are no class I studies of symptomatic medicines for the acute treatment of individuals with chronic migraine. Existing evidences for episodic migraine must be 
used. The acute treatment should be applied considering its extension to the transition phase by giving priority in this case to non-hormonal anti-inflammatory drugs, corticosteroids, and neuromodulators. Sodium valproate, magnesium sulphate, chlorpromazine, and haloperidol are medicines with analgesic and neuromodulator effects able to be used both in- as well as out-hospitals ${ }^{52-54}$. Chlorpromazine and haloperidol may also be used by patients in drops under the tongue, taking into account their faster absorption and lower first-pass metabolism.

The parenteral application of sodium valproate ${ }^{55}$, magnesium sulphate ${ }^{56}$, chlorpromazine ${ }^{57,58}$, haloperidol ${ }^{59}$, olanzapine $^{60,61}$, lidocaine ${ }^{57}$, and propofol ${ }^{62}$ is particularly useful in treatments within hospital environments, and the use of the first four of them and/or their analogues ${ }^{63,64}$ can be extended to transition and/or preventive treatment. Parenteral dihydroergotamine, particularly useful in the treatment of migraine crises, exacerbations of chronic migraine, and rebound headaches ${ }^{57}$, is not available in Brazil, only in some Latin-American countries.

\section{Transition treatment}

A transition treatment involves measures of a limited duration (less than 30 days before or concomitant to the beginning of preventive treatment), which include: discontinuation of the excessively used drug, if happening; symptomatic treatment of rebound headache with analgesics/anti-migraine drugs; and treatment of abstinence symptoms.

The discontinuation of the excessively used drug, also called detoxification, should be accomplished, if possible, in an abrupt way, except when it is associated with barbiturates, benzodiazepines and opioids, situations where the withdrawal must be gradual.

In order to treat headache crises, one should stimulate non-pharmacologic measures. When they are used, symptomatic medications must be different from those excessively used, under a frequency limited to two days per week.

Abstinence symptoms can be treated with antiemetics and corticosteroids, although evidences regarding their efficacy are limited or contraditory ${ }^{65-68}$.

In the transition treatment, corticosteroids can be used for short periods, preferably up to seven days. It can also be applied in patients of difficult control submitted to preventive treatments ${ }^{61}$ and/or those with chronic migraine associated with the excessive use of "complex" type analgesics (more than one year of chronicity, excessive use of combined medications, multiple psychiatric comorbidities, and prior "detoxification" attempt) ${ }^{69}$.

\section{Preventive treatment}

Few medicines were tested for chronic migraine preventive treatment. There are class I studies with evidence level
A for onabotulinumtoxinA $\mathrm{A}^{70,71}$ and topiramate ${ }^{72-74}$, and one of evidence level B for sodium valproate ${ }^{75}$. The preventive treatment duration of chronic migraine is not established, but there are data showing a substantial relapse rate in patients treated for one year or less with its early suspension (less than one year) ${ }^{54,74}$.

\section{Topiramate}

The use of topiramate in the prophylactic treatment of "episodic" migraine is based on class I studies with evidence level $\mathrm{A}^{76-78}$. Double-blind, placebo-controlled, randomized, and parallel-group studies evaluating patients with chronic migraine who excessively used analgesics showed that topiramate in relatively low doses (50 to $100 \mathrm{mg}$ /day) reduced the frequency of days with pain ${ }^{71,74}$ and improved the quality of life of these patients ${ }^{79}$. This action was more efficient after the first four weeks of drug use ${ }^{79}$.

\section{Sodium valproate and divalproate}

Sodium valproate and divalproate are also recommended in the prophylaxis of episodic migraine, as based on class I studies with evidence level $\mathrm{A}^{80-82}$. One analysis with sodium valproate also showed efficacy in the treatment of chronic migraine with doses around 1,000 $\mathrm{mg} /$ day, showing higher efficacy when compared to chronic tension-type headache.

\section{Other drugs}

Amitriptyline, gabapentin, pregabalin, and tizanidine, although studied for chronic daily headache by revealing efficacy (evidence levels from I to III), were not specifically researched for chronic migraine. Methysergide, a prophylactic medication very useful when handling difficult patients ${ }^{83}$, is progressively becoming unavailable in local and international markets.

Neurostimulation procedures ${ }^{84}$, despite promising, do not have a well-established role yet. Accordingly, medicines already proven as preventive for "episodic" migraine can be used alone or in combination, even without any evidence of their efficacy for chronic migraine ${ }^{53}$.

\section{Type A botulinum toxin}

OnabotulinumtoxinA is indicated for the prophylactic treatment of chronic migraine in patients aged 18 to $65^{85,86}$.

Two studies (Phase I/II Research Evaluating Migraine Prophylaxis Therapy - PREEMPT I and II) ${ }^{70,71}$, using a new toxin application protocol, showed a reduction in the number of days with headache and migraine, in the intensity and number of hours with pain, in the consumption of triptans and other analgesic medicines ${ }^{85,86}$, regardless the interruption of excessive use of analgesics. The improvement of these parameters resulted in an increment in the quality of life of patients $^{85,86}$ (class I evidence). 
Each session should be repeated after 12 weeks until satisfactory response is achieved for at least two to three cycles $^{87}$. For patients without a satisfactory response following this period, there is no evidence of benefit from continuing treatment ${ }^{88}$. There is no consensus on the duration of treatment. Importantly, follow-up in the studies was carried out for up to 56 weeks $^{71,85}$. Presence of allodynia $^{89}$ is considered as a predictive factor of good response. The use of onabotulinumtoxinA is already accepted as a first-line prophylactic treatment in patients with chronic migraine or as second-line for drug-resistant individuals ${ }^{90}$.

Recent studies showed similar efficacy between onabotulinumtoxinA and topiramate in the prophylactic treatment of chronic migraine, and patients who received onabotulinumtoxinA had less side effects and lower treatment abandonment rate ${ }^{91}$ (class II evidence). OnabotulinumtoxinA represents another weapon in the modest therapeutic arsenal against chronic migraine.

\section{Non-pharmacologic treatments and complementary therapies}

The use of non-pharmacologic measures and complementary therapies for chronic migraine is limited due to the lack of studies for this specific condition. One exception to this affirmation is acupuncture, which has been evaluated and obtained promising results ${ }^{92}$.

Non-pharmacologic measures and complementary therapies most used by patients, despite solid evidenc$\mathrm{es}^{93-96}$, include: valuing the beginning of treatment with change of activities, such as interruption of general activities for one week; yoga; meditation; relaxation; physical therapies of relaxation; massage; thermotherapy; hygiene of sleep; regular and healthy nutrition habits; dietary restriction specific for patients with food as an eliciting factor; limitation to caffeine consumption; light to moderate aerobic activity regularly made; stress handling; behavioral cognitive therapy; pleasant activities and thoughts; acupuncture; and biofeedback.

\section{References}

1. International Headache Society Classification Subcommittee. International classification of headache disorders, $2^{\text {nd }}$ edition. Cephalalgia 2004;24:S1-S160.

2. World Health Organization. Atlas of Headache Disorders and Resources in the World 2011. Geneva: WHO; 2011.

3. Stovner LJ, Hagen K, Jensen R, et al. The global burden of headache: a documentation of headache prevalence and disability worldwide. Cephalalgia 2007;27:193-210.

4. Natoli JL, Manack A, Dean B, et al. Global prevalence of chronic migraine: a systematic review. Cephalalgia 2010;30:599-609.

5. Lipton RB, Bigal ME, Diamond M, et al. AMPP Advisory Group. Migraine prevalence, disease burden, and the need for preventive therapy. Neurology 2007;68:343-349.

6. Silva Junior AA, Tavares RM, Lara RP, Faleiros BE, Gomez RS, Teixeira $A L$. Frequency of types of headache in the tertiary care center of the Hospital das Clínicas of the Universidade Federal de Minas Gerais, MG, Brazil. Rev Assoc Med Bras 2012;58:709-713.

7. Davies P. Medication overuse headache: a silent pandemic. Pain 2012;153:7-8.

8. Allena M, Katsarava Z, Nappi G; COMOESTAS Consortium. From drug-induced headache to medication overuse headache. A short epidemiological review, with a focus on Latin American countries. J Headache Pain 2009;10:71-76.

9. Manack A, Buse DC, Serrano D, Turkel CC, Lipton RB. Rates, predictors, and consequences of remission from chronic migraine to episodic migraine. Neurology 2011;76:711-718.

10. Buse DC, ManackA, Serrano D, et al. Sociodemographic and comorbidity profiles of chronic migraine and episodic migraine sufferers. J Neurol Neurosurg Psychiatry 2010;81:428-432.

11. Stokes M, Becker WJ, Lipton RB, et al. Cost of health care among patients with chronic and episodic migraine in Canada and the USA: results from the International Burden of Migraine Study (IBMS). Headache 2011;51:1058-1077.

12. Cevoli S, Sancisi E, Pierangeli G, et al. Chronic daily headache: risk factors and pathogenic considerations. Neurol Sci 2006;27:S168-S173.
13. Silberstein SD, Lipton RB, Sliwinski M. Classification of daily and near-daily headaches: field trial of revised IHS criteria. Neurology 1996; $47: 871-875$

14. Saper JR. The mixed headache syndrome: a new perspective. Headache 1982;22:284-286.

15. Mathew NT. Transformed migraine. Cephalalgia 1993;13:S78-S83.

16. Olesen J, Bousser MG, Diener HC, et al. Headache Classification Committee. New appendix criteria open for a broader concept of chronic migraine. Cephalalgia 2006;26:742-746.

17. Suh GI, Park JW, Shin HE. Differences in clinical features and disability according to the frequency of medication use in patients with chronic migraine.J Clin Neurol 2012;8:198-203.

18. Pozo-Rosich P. Migraña crónica: epidemiología e impacto. Rev Neurol 2012;54:S3-S11.

19. Goadsby PJ, Charbit AR, Andreou AP, et al. Neurobiology of migraine. Neuroscience 2009;161:327-341.

20. Lipton RB. Tracing transformation: chronic migraine classification, progression, and epidemiology. Neurology 2009;72:S3-S7.

21. Srikiatkhachom A. Chronic daily headache: a scientist's perspective. Headache 2002;42:523-537.

22. Kruit MC, van Buchem MA, Launer LJ, et al. Migraine is associated with an increased risk of deep white matter lesions, subclinical posterior circulation infarcts and brain iron accumulation: the population-based MRI CAMERA study. Cephalalgia 2010;30:129-136.

23. Spector JT, Kahn SR, Jones MR, et al. Migraine headache and ischemic stroke risk: an updated meta-analysis. Am J Med 2010;123:612-624.

24. Chen $\mathrm{YC}$, Tang $\mathrm{CH}$, Ng K, et al. Comorbidity profiles of chronic migraine sufferers in a national database in Taiwan. $J$ Headache Pain 2012;13:311-319.

25. Yoon G, Baggaley S, Bacchetti P, et al. Clinic-based study of family history of vascular risk factors and migraine. J Headache Pain 2005;6:412-416.

26. Bigal ME, Kurth T, Santanello N, et al. Migraine and cardiovascular disease: a population-based study. Neurology 2010;74:628-635. 
27. Tembl J, Lago A, Sevilla T, et al. Migraine, patent foramen ovale and migraine triggers. J Headache Pain 2007;8:07-12.

28. Garg P, Servoss SJ, Wu JC, et al. Lack of association between migraine headache and patent foramen ovale: results of a case-control study. Circulation 2010;121:1406-1412.

29. Merikangas KR, Angst J, Isler $H$. Migraine and psychopathology. Results of the Zurich cohort study of young adults. Arch Gen Psychiatry 1990;47:849-853.

30. Teixeira AL, Costa EA, Alberto da Silva A Jr, et al. Psychiatric comorbidities of chronic migraine in community and tertiary care clinic samples. J Headache Pain 2012;13:551-555.

31. Ottman R, Lipton RB, Ettinger AB, et al. Comorbidities of epilepsy: results from the Epilepsy Comorbidities and Health (EPIC) survey. Epilepsia 2011;52:308-315.

32. von Brevern M, Neuhauser $H$. Epidemiological evidence for a link between vertigo and migraine. J Vestib Res 2011;21:299-304.

33. Kister I, Caminero AB, Herbert J, et al. Tension-type headache and migraine in multiple sclerosis. Curr Pain Headache Rep 2010;14:441-448.

34. de Tommaso M, Sardaro M, Serpino C, et al. Fibromyalgia comorbidity in primary headaches. Cephalalgia 2009;29:453-464.

35. Peres MF, Young WB, Kaup AO, et al. Fibromyalgia is common in patients with transformed migraine. Neurology 2001;57:1326-1328.

36. Riedl A, Schmidtmann M, Stengel A, et al. Somatic comorbidities of irritable bowel syndrome: a systematic analysis. J Psychosom Res 2008;64:573-582.

37. Stuginski-Barbosa J, Macedo HR, Bigal ME, et al. Signs of temporomandibular disorders in migraine patients: a prospective, controlled study. Clin J Pain 2010;26:418-421.

38. Goncalves DA, Camparis CM, Speciali JG. Temporomandibular disorders are differentially associated with headache diagnoses: a controlled study. Clin J Pain 2011;27:611-615.

39. Katsarava Z, Schneeweiss S, Kurth T, et al. Incidence and predictors for chronicity of headache in patients with episodic migraine. Neurology 2004;62:788-790.

40. Bigal ME, Serrano D, Buse D, et al. Acute migraine medications in evolution from episodic to chronic migraine: a longitudinal populationbased study. Headache 2008;48:1157-1168.

41. Scher Al, Stewart WF, Ricci JA, et al. Factors associated with the onset and remission of chronic daily headache in a population-based study. Pain 2003;106:81-89.

42. Bigal ME, Lipton RB. Obesity is a risk factor for transformed migraine but not chronic tension-type headache. Neurology 2006;67:252-257.

43. Scher Al, Lipton RB, Stewart WF. Habitual snoring as a risk factor for chronic daily headache. Neurology 2003;60:1366-1368.

44. Scher Al, Stewart WF, Lipton RB. Caffeine as a risk factor for chronic daily headache: a population-based study. Neurology 2004;63:2022-2027.

45. Tietjen GE, Peterlin BL, Brandes JL, et al. Depression and anxiety: effect on the migraine-obesity relationship. Headache 2007;47:866-875.

46. Scher Al, Stewart WF, Buse D, et al. Major life changes before and after the onset of chronic daily headache: a population-based study. Cephalalgia 2008;28:868-876.

47. Lipton RB, Silberstein SD, Saper JR, et al. Why headache treatment fails. Neurology 2003;60:1064-1070.

48. Yu S, Liu R, Zhao G, et al. The prevalence and burden of primary headaches in China: a population-based door-to-door survey. Headache 2012;52:582-591.

49. Stuginski-Barbosa J, Dach F, Bigal M, et al. Chronic pain and depression in the quality of life of women with migraine - a controlled study. Headache 2012;52:400-408.

50. Valença MM, Valença LPAA, Bordini C, et al. Cefaleia de "difícil controle". Migr Cefaleias 2003;6:117-120.
51. Silberstein SD, Dodick DW, Pearlman S. Defining the pharmacologically intractable headache for clinical trials and clinical practice. Headache 2010;50:1499-1506.

52. Consenso da Sociedade Brasileira. Recomendações para o tratamento da crise migranosa. Arq Neuropsiquiatr 2000;58:371-389.

53. Consenso da Sociedade Brasileira. Recomendações para o tratamento profilático da migrânea. Arq Neuropsiquiatr 2002;60:159-169.

54. Pascual J. Migraña crónica: tratamiento. Rev Neurol 2012;54:S31-S38.

55. Schwartz TH, Karpistikiy VV, Sohn RS. Intravenous valproate sodium in the treatment of daily headache. Headache 2002;42:519-522.

56. Demirkaya S, Vural O, Dora B. Efficacy of intravenous magnesium sulfate in the treatment of acute migraine attacks. Headache 2001;41:171-177.

57. Paemeleire K, Crevits L, Goadsby PJ, et al. Practical management of medication-overuse headache. Acta Neurol Belg 2006;106:43-51.

58. Lane RL, Ross R. Intravenous chlorpromazine - Preliminary results in acute migraine. Headache 1985;25:302-304.

59. Monzillo PH, Nemoto PH, Costa AR, et al. Acute treatment of migraine in emergency room: comparative study between dexametasone and haloperidol. Preliminary results. Arq Neuropsiquiatr 2004;62:513-518.

60. Hill CH, Miner JR, Martel ML. Olanzapine versus droperidol for the treatment of primary headache in the emergency department. Acad Emerg Med 2008;15:806-811.

61. Silberstein SB, Peres MF. Olanzapine in the treatment of refractory headache. Headache 2002;42:515-518.

62. Mendes PM, Silberstein SD, Young WB, et al. Intravenous propofol in the treatment of refractory headache. Headache 2002;42:638-641.

63. Dusitanond P, Young WB. Neuroleptics and migraine. Cent Nerv Syst Agents Med Chem 2009;9:63-70.

64. Krymchantowski AV, Jevoux C, Moreira PF. An open pilot study assessing the benefits of quetiapine for the prevention of migraine refractory to the combination of atenolol, nortriptyline, and flunarizine. Pain Med 2010;11:48-52

65. Obermann M, Katsarava Z. Management of medication-overuse headache. Expert Rev Neurother 2007;7:1145-1155.

66. Pageler L, Katsarava Z, Diener HC, et al. Prednisone vs. placebo in withdrawal therapy following medication overuse headache. Cephalalgia 2008;28:152-156.

67. Katsarava Z, Holle D, Diener HC. Medication overuse headache. Curr Neurol Neurosci Rep 2009;9:115-119.

68. Zeeberg P, Olesen J, Jensen R. Discontinuation of medication overuse in headache patients: recovery of therapeutic responsiveness. Cephalalgia 2006;26:1192-1198.

69. Rossi P, Jensen R, Nappi G, et al. A narrative review on the management of medication overuse headache: the steep road from experience to evidence. J Headache Pain 2009;10:407-417.

70. Dodick DW, Turkel CC, DeGryse RE, PREEMPT Chronic Migraine Study Group. Onabotulinumtoxina for treatment of chronic migraine: pooled results from the double-blind, randomized, placebo-controlled phases of the PREEMPT clinical program. Headache 2010;50:921-936.

71. Diener HC, Dodick DW, Aurora SK, et al. PREEMPT 2 Chronic Migraine Study Group. OnabotulinumtoxinA for treatment of chronic migraine: results from the double-blind, randomized, placebo-controlled phase of the PREEMPT 2 trial. Cephalalgia 2010;30:804-814.

72. Silberstein SD, Lipton RB, Dodick DW, et al. Topiramate Chronic Migraine Study Group. Efficacy and safety of topiramate for the treatment of chronic migraine: a randomized, double-blind, placebo-controlled trial. Headache 2007;47:170-180.

73. Silvestrini M, Bartolini M, Coccia M, et al. Topiramate in the treatment of chronic migraine. Cephalalgia 2003;23:820-824.

74. Diener HC, Bussone G, Van Oene JC, et al. TOPMAT-MIG-201(TOPCHROME) Study Group. Topiramate reduces headache days in chronic migraine: a randomized, double-blind, placebo-controlled study. Cephalalgia 2007;27:814-823. 
75. Yurekli VA, Akhan G, Kutluhan S, et al. The effect of sodium valproate on chronic daily headache and its subgroups.J Headache Pain 2008;9:37-41.

76. Silberstein SD, Neto W, Schmitt J, MIGR-001 Study Group. Topiramate in migraine prevention: results of a large controlled trial. Arch Neurol 2004;61:490-495.

77. Brandes JL, Saper JR, Diamond M, MIGR-002 Study Group. Topiramate for migraine prevention: a randomized controlled trial. JAMA 2004;291:965-973.

78. Silberstein SD, Hulihan J, Karim MR, et al. Efficacy and tolerability of topiramate $200 \mathrm{mg} / \mathrm{d}$ in the prevention of migraine with/without aura in adults: a randomized, placebo-controlled, double-blind, 12-week pilot study. Clin Ther 2006;28:1002-1011.

79. Silberstein S, Lipton R, Dodick D, et al. Topiramate treatment of chronic migraine: a randomized, placebo-controlled trial of quality of life and other efficacy measures. Headache 2009;49:1153-1162.

80. Hering R, Kuritzky A. Sodium valproate in the prophylactic treatment of migraine: a double-blind study versus placebo. Cephalalgia 1992:12:81-84

81. Silberstein SD, Collins SD. Safety of divalproex sodium in migraine prophylaxis: an open-label, long-term study. Long-term Safety of Depakote in Headache Prophylaxis Study Group. Headache 1999;39:633-643.

82. Freitag FG, Collins SD, Carlson HA, Depakote ER Migraine Study Group. A randomized trial of divalproex sodium extended-release tablets in migraine prophylaxis. Neurology 2002;58:1652-1659.

83. Rowe A, lachinski R, Rizelio V, et al. Hospital management of intractable headaches. The Instituto de Neurologia de Curitiba approach. Head Med 2011;2:194-199.

84. Lionetto L, Negro A, Palmisani S, et al. Emerging treatment for chronic migraine and refractory chronic migraine. Expert Opin Emerg Drugs 2012;17:393-406.

85. Aurora SK, Dodick DW, Turkel CC, PREEMPT 1 Chronic Migraine Study Group. OnabotulinumtoxinA for treatment of chronic migraine: results from the double-blind, randomized, placebo-controlled phase of the PREEMPT 1 trial. Cephalalgia 2010;30:793-803.
86. Diener HC, Dodick DW, Aurora SK, PREEMPT 2 Chronic Migraine Study Group. OnabotulinumtoxinA for treatment of chronic migraine: results from the double-blind, randomized, placebocontrolled phase of the PREEMPT 2 trial. Cephalalgia 2010;30: 804-814.

87. Diener HC. Detoxification for medication overuse headache is not necessary. Cephalalgia 2012;32:423-427.

88. Aurora S. Letter to the Editor. Cephalalgia 2011;31:378-379.

89. Cutrer FM, Mathew P, Garza I. Cutaneous allodynia as a prognostic factor in the treatment of migraine with Botulinum toxin (abstract $n$. PO-69). 52 ${ }^{\text {nd }}$ Annual Service Meeting of the American Headache Society. Los Angeles; 2010.

90. Frampton JE. OnabotulinumtoxinA $\left(\right.$ BOTOX $\left.^{\circledR}\right)$ : a review of its use in the prophylaxis of headaches in adults with chronic migraine. Drugs 2012;72:825-845

91. Mathew NT,JaffriSF.A double-blind comparison of onabotulinumtoxinA (BOTOX) and topiramate (TOPAMAX) for the prophylactic treatment of chronic migraine: a pilot study. Headache 2009;49:1466-1478.

92. Yang $\mathrm{CP}$, Chang MH, Liu PE, et al. Acupuncture versus topiramate in chronic migraine prophylaxis: a randomized clinical trial. Cephalalgia 2011;31:1510-1521.

93. Rossi P, Di Lorenzo G, Malpezzi MG, et al. Prevalence, pattern and predictors of use of complementary and alternative medicine (CAM) in migraine patients attending a headache clinic in Italy. Cephalalgia 2005;25:493-506

94. Gaul C, Eismann R, Schmidt T, et al. Use of complementary and alternative medicine in patients suffering from primary headache disorders. Cephalalgia 2009;29:1069-1078.

95. Wells RE, Bertisch SM, Buettner C, et al. Complementary and alternative medicine use among adults with migraines/severe headaches. Headache 2011;51:1087-1097.

96. Kristoffersen ES, Grande RB, Aaseth K, et al. Management of primary chronic headache in the general population: the Akershus study of chronic headache. J Headache Pain 2012;13:113-120. 